\title{
STUDY OF HYBRID CASCADE MULTI-LEVEL INVERTER BASED ON SVPWM TECHNOLOGY
}

\author{
Zhu Feng ${ }^{1}$, Rebeca Miranda-Castro ${ }^{1}$, Wolfgang Schmickler ${ }^{1}$ \\ ${ }^{1}$ Industrial technology school of Suzhou industrial park electronical technology system, \\ Jiangsu Suzhou, 215000, China
}

\begin{abstract}
Space Vector Pulse Width Modulation (SVPWM) technology has higher voltage utilization, lower instantaneous rate of change and smaller total harmonic distortion than Sinewave Pulse Width Modulation (SPWM), and is more suitable for digitization To achieve, so more and more attention. SVPWM technology can be applied to cascaded multilevel converters to achieve lower voltage fluctuation and smaller harmonic distortion. It can be seen from the simulation and experiment that SVPWM technology can be applied to cascade Multi-level converter, the output voltage fluctuation rate is small, the overall utilization rate is higher.
\end{abstract}

Keywords: Space Vector Pulse Modulation, Sinusoidal Pulse Width Modulation, Cascaded Multilevel Converters, Harmonic Distortion.

\section{Introduction}

Among the various inverter architectures, the multilevel output voltage generated by the cascaded multi-level cascaded Inverters circuit architecture has the minimum total Harmonic Distortion (THD) and can reduce the generation of electromagnetic interference (EMI) when the voltage is applied.

The more hierarchical outputs, the lower the EMI.

Therefore, this architecture has been widely used in high power electronic systems [1-3].

Pulse width modulation (PWM) is the most widely used technology for converters, such as Sinusoidal Pulse Width Modulation (SPWM), Space Vector Pulse Width Modulation (SVPWM). SPWM is a traditional modulation method, which has the advantages of simple principle and easy control.

Compared with SPWM, SVPWM has higher availability of voltage, lower instantaneous rate of change of voltage and smaller total harmonic distortion, which is more suitable for digital implementation, so more and more attention has been paid to [4-6]. Due to the rapid development of Microcontrollers in recent years, a variety of chips with excellent performance have been developed continuously, which have the characteristics of powerful function, cheap price and convenient application. In many circuits, the control technology can be realized by digital control. These chips have the function of programmable design, through calculation [7]. Based on the above advantages and trends, this paper uses MATLAB / Simulink to construct the control module of SVM and the main circuit structure of cascaded multilevel converter, and uses simulation to verify the feasibility of the system.
The control of cascaded multilevel converters by space vector pulse width modulation (SVPWM) technology is realized by field experiments using microcontroller and programmable logic modules.

\section{Analysis of System Architecture}

Figure 1 shows a block diagram of a digitally controlled cascaded multilevel converter. The digital control circuit contains a microcontroller and a Programmable Logic Device (CPLD). The cascade multilevel converter circuit includes the gate drive circuit, the converter main circuit.

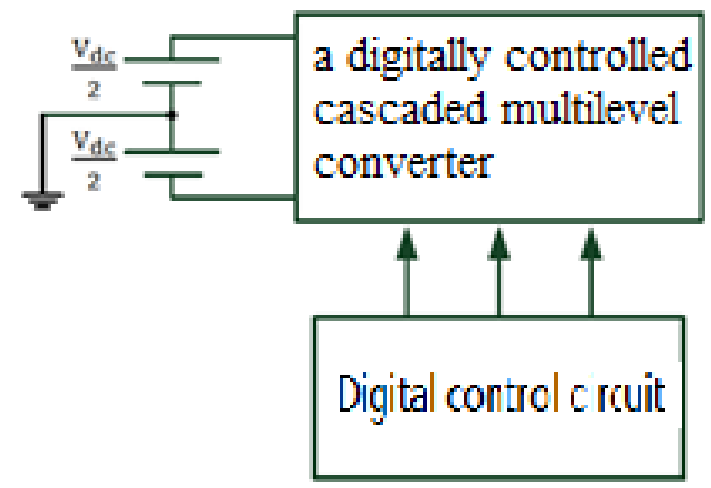

Figure 1: Block diagram of digitally controlled cascaded multilevel converter

Fig. 2 is the system architecture. The output voltage and frequency are determined according to the system parameter setting, and the PWM control signal is generated by the operation of threedimensional voltage space vector pulse width adjustment. Then the control signal of the gate is 
generated by processing the switch signal and the blank time through the programmable logic module, and then through the gate drive.
The power circuit is used to control the power switch of the main circuit of the cascaded multilevel converter to generate multilevel voltage output [8].

digital control circuit

a digitally controlled cascaded multilevel converter

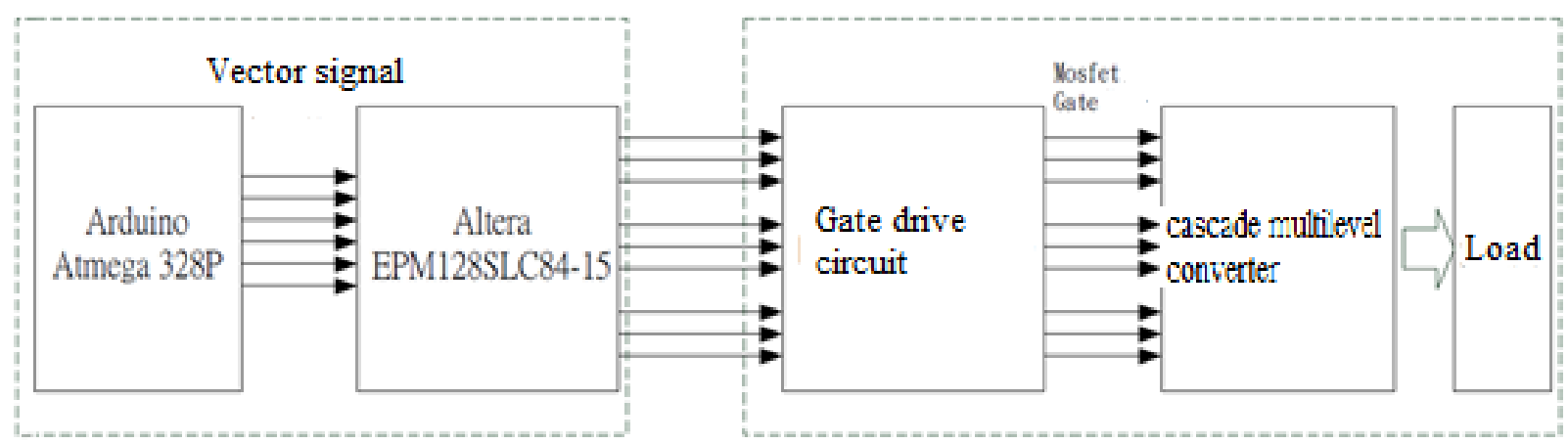

Figure 2: Block diagram of system architecture

\section{The Basic Principles of SVPWM Technology}

The space vector representation is that three-phase voltage used in the voltage (current), which is the phase difference of 120 degrees, in a complex space plane is 120 degrees, and the three-phase voltage (current) in the complex space plane can be synthesized a voltage (current) vector, can also be decomposed into two orthogonal components (as shown in Fig. 3) [9].

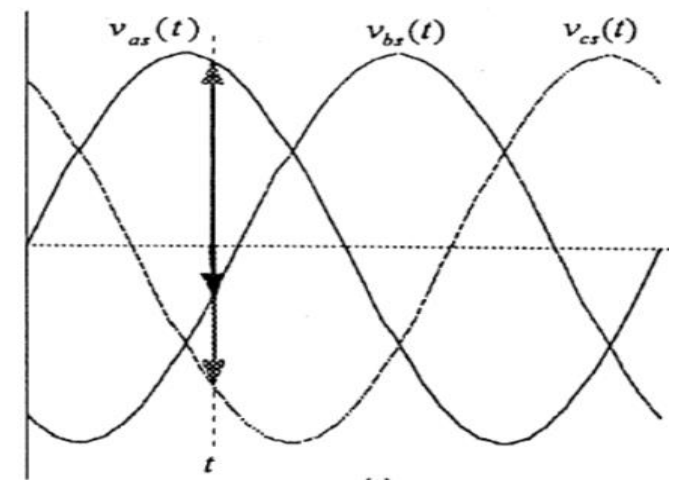

Figure 3: three-phase AC voltage

Three phase voltage is mathematically expressed as:

$$
\begin{aligned}
& v_{a}=V_{m} \sin \omega t \\
& v_{b}=V_{m} \sin \left(\omega t-120^{\circ}\right) \\
& v_{\mathrm{c}}=V_{m} \sin \left(\omega t+120^{\circ}\right)
\end{aligned}
$$

Fig. 3 shows that the three-phase voltage (current) originally represented by AC sine can be represented by a voltage (current) vector in a space vector plane.

Based on the concept [10], the 6 switches (S1, S2, S3, S4, S5, S6) of the converter are represented (shown in Fig. 4).

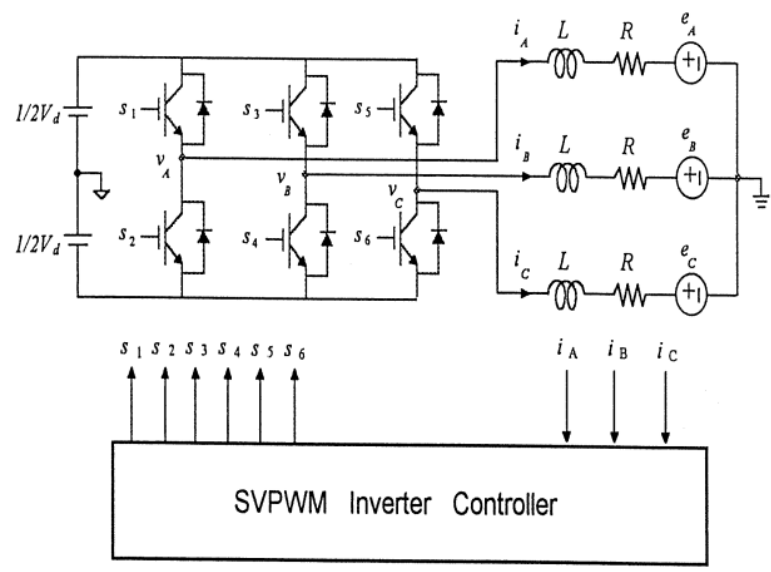

Figure 4: Application of SVPWM technology in cascaded multilevel converter

The basic converter consists of three sets of switches composed of power electronic components, as shown in Fig.4. In order to prevent the upper and lower power electronic components of the same group from conducting at the same time and causing short circuit damage, the switching action of the upper and lower power electronic components of the same group must be opposite. So, the real switching action is three sets in turn and each group has two states. The number of switching state of the converter is 8 . If " 1 " means that the upper switch is on, the lower switch is off; if "0" means that the upper switch is off, the lower switch is on.

There are eight states in Fig. 5 (a), which can be defined as eight voltage space vectors (V1, V2, V3,... V8), which contains six voltage vectors of non zero and voltage vectors of two zero [11].

In theory, the voltage vector of zero represents three groups of power electronic components connected to a positive source or ground at the same time.

This voltage space vector can form a positive hexagon, as shown in Fig. 5 (b). 


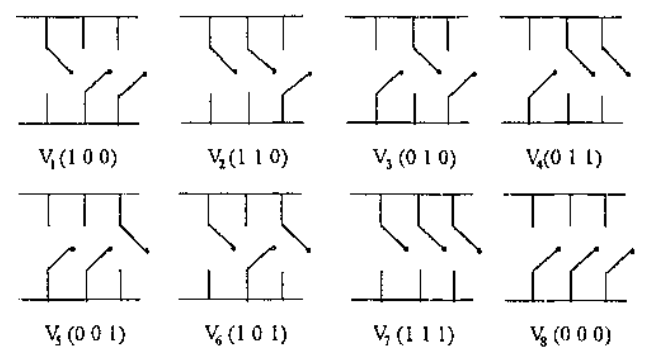

(a)

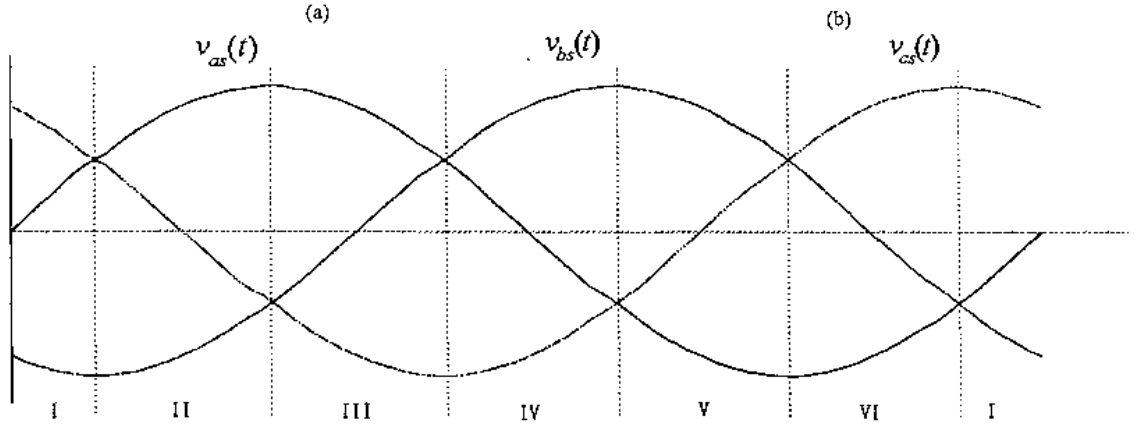

(c)

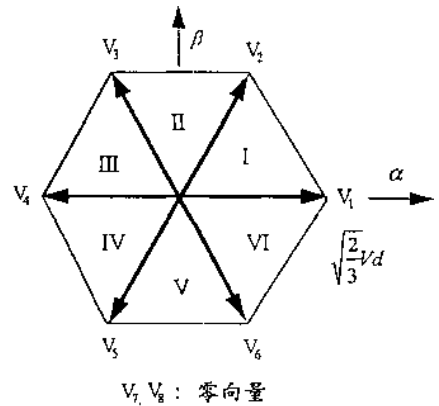

(b)

Figure 5: (a) the switching state of the converter and the corresponding phase (b) vector diagram (c) of the input phase voltage section.

If viewed clockwise, the phase sequence is $\boldsymbol{V}_{1} \sim \boldsymbol{V}_{6} \sim \boldsymbol{V}_{5} \sim \boldsymbol{V}_{2} \sim \boldsymbol{V}_{\boldsymbol{1}}$ changing, so by the relationship between the phase sequence and the switching action, a table can be listed, as shown in Table 1.

The space vector pulse width modulation (SVPWM) method is to control the eight basic voltage vectors and their maintenance time. Under the premise of minimizing flux ripple and switching frequency, the air gap flux vector trajectory generated by induction motor is approximated to an ideal circle. How to use these eight voltage vectors to achieve this goal can be explained from the two viewpoints of average voltage vector and flux vector [12].

Table 1: Relationship between phase sequence of space voltage vector and switching action of converter

\begin{tabular}{|c|c|c|c|c|c|c|c|c|}
\hline No. & $\mathrm{V}_{1}$ & $\mathrm{~V}_{6}$ & $\mathrm{~V}_{5}$ & $\mathrm{~V}_{4}$ & $\mathrm{~V}_{3}$ & $\mathrm{~V}_{2}$ & $\mathrm{~V}_{7}$ & $\mathrm{~V}_{0}$ \\
\hline $\mathrm{S}_{1}$ & 1 & 1 & 0 & 0 & 0 & 1 & 1 & 0 \\
\hline $\mathrm{S}_{3}$ & 0 & 1 & 1 & 1 & 0 & 0 & 1 & 0 \\
\hline $\mathrm{S}_{5}$ & 0 & 0 & 0 & 1 & 1 & 1 & 1 & 0 \\
\hline $\mathrm{S}_{2}$ & 0 & 0 & 1 & 1 & 1 & 0 & 0 & 1 \\
\hline $\mathrm{S}_{4}$ & 1 & 0 & 0 & 0 & 1 & 1 & 0 & 1 \\
\hline $\mathrm{S}_{6}$ & 1 & 1 & 1 & 0 & 0 & 0 & 0 & 1 \\
\hline $\mathrm{V}_{\mathrm{ao}}$ & $\mathrm{E} / 2$ & $\mathrm{E} / 2$ & $-\mathrm{E} / 2$ & $-\mathrm{E} / 2$ & $-\mathrm{E} / 2$ & $\mathrm{E} / 2$ & $\mathrm{E} / 2$ & $-\mathrm{E} / 2$ \\
\hline $\mathrm{V}_{\mathrm{bo}}$ & $-\mathrm{E} / 2$ & $\mathrm{E} / 2$ & $\mathrm{E} / 2$ & $\mathrm{E} / 2$ & $-\mathrm{E} / 2$ & $-\mathrm{E} / 2$ & $\mathrm{E} / 2$ & $-\mathrm{E} / 2$ \\
\hline $\mathrm{V}_{\mathrm{co}}$ & $-\mathrm{E} / 2$ & $-\mathrm{E} / 2$ & $-\mathrm{E} / 2$ & $\mathrm{E} / 2$ & $\mathrm{E} / 2$ & $\mathrm{E} / 2$ & $\mathrm{E} / 2$ & $-\mathrm{E} / 2$. \\
\hline $\mathrm{V}_{\mathrm{ab}}$ & $\mathrm{E}$ & 0 & $-\mathrm{E}$ & $-\mathrm{E}$ & 0 & $\mathrm{E}$ & 0 & 0 \\
\hline $\mathrm{V}_{\mathrm{bc}}$ & -0 & $\mathrm{E}$ & $\mathrm{E}$ & 0 & $-\mathrm{E}$ & $-\mathrm{E}$ & 0 & 0 \\
\hline $\mathrm{V}_{\mathrm{ca}}$ & $-\mathrm{E}$ & $-\mathrm{E}$ & 0 & $\mathrm{E}$ & $\mathrm{E}$ & 0 & 0 & 0 \\
\hline
\end{tabular}

\section{Simulation Experimental Results}

\subsection{Simulation analysis}

Combining the basic principle of SVPWM technology, the control module of SVPWM and the main circuit structure of cascaded multilevel converter are constructed based on MATLAB Simulink, and the above-mentioned regulation is realized by simulation.

We use MATLAB SIMULINK to build a cascaded multilevel converter system block diagram using SVPWM as shown in Figure 6, which contains six system block diagrams. 


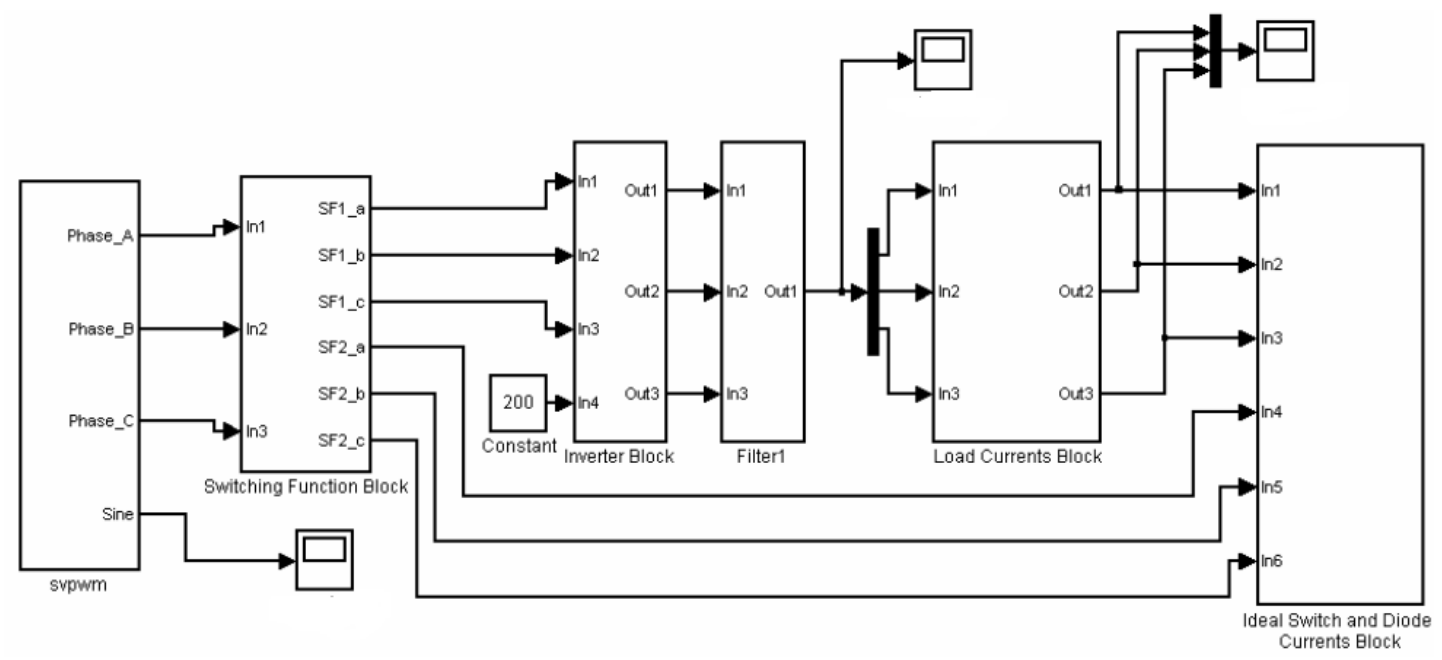

Figure 6: SIMULINK simulation block diagram of cascaded multilevel converter controlled by SVPWM

In the block diagram of SVPWM, PWM signal and three-phase sine wave voltage wave form is produced. The internal structure is shown in Fig. 7. According to the above principle, the first step is to generate a carrier with known frequency fc and carrier period Tc $=1 / \mathrm{fc}$, which is generated by the Carrier block in Fig. 7.

The structure is shown in Fig. 8.

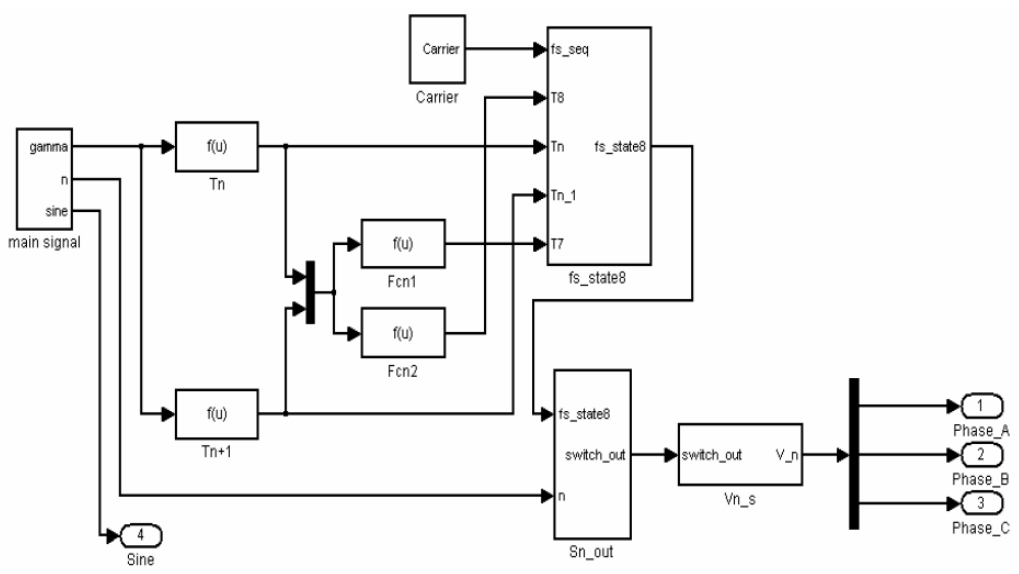

Figure 7: Block diagram of SVPWM system

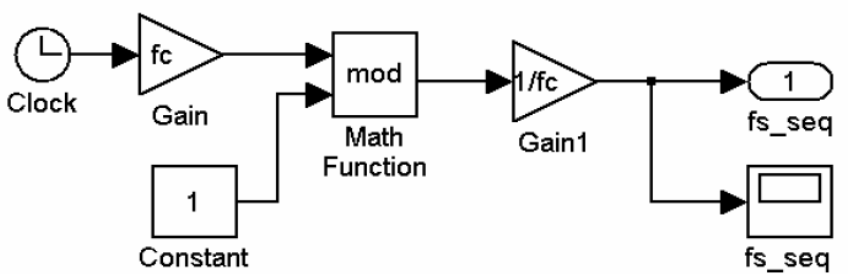

Figure 8: The generation of Carrier block diagram

According to the angle of each increment in the voltage vector plane is $\gamma=T_{C} / T{ }^{*} \pi$, when $\gamma$ increases gradually, Vref will enter the second, third, and In region II, III, ..., VI, although the range of $\gamma$ angle varies from $0^{\circ} \sim 360^{\circ}$, careful observation shows that the range of $\gamma$ angle varies from $0^{\circ} \sim 60^{\circ}$ in each interval.

It can be obtained:

$$
T_{n}=\frac{\sin \left(60^{\circ}-\lambda\right)}{\sin 60^{\circ}} \cdot T_{z} \cdot a
$$

$$
T_{n+1}=\frac{\sin \gamma}{\sin 60^{\circ}} \cdot T_{z} \cdot a
$$

Therefore, in the block diagram of Figure 8, each interval (n) is divided according to the size of the reference voltage Vref frequency $\mathrm{f}$, and the variation range of $\gamma$ is between 0 and 60 degrees.

Then, the time needed for each interval voltage vector and zero voltage vector, $T_{n} 、 T_{n+1} 、 T_{7}$ and $T_{8}$, is calculated by using Figure 9. Send it to the fs_state8 block diagram (Fig. 10) and cut out eight 
switching times in one carrier cycle. The rotating voltage vector Vref is synthesized using different space vectors in different intervals. Therefore, we can use the Sn_out block diagram (Fig. 11) to determine the switching time in each of the eight switching times in a carrier cycle. Voltage vector required.

Finally, the $V n_{-} s$ block diagram (Fig. 12) is used to generate the switching mode of the voltage vector needed for each switching period.

Signals generated by SVPWM block diagrams are sent to witching Function、inverter、Filter、 load
currents、Ideal Switch and Diode Current. block diagrams to verify the results. The computer simulation results are shown in Fig. 13 17.

The simulation parameters are as follows: DC input voltage $V_{d c}=200, f=60 \mathrm{~Hz}, f_{c}=10, M=1$, $R=10 \Omega, L=20 \mathrm{mH}$. Fig. 13 is voltage space vector wave width modulation waveform of each section. Fig.14 is output voltage waveform $V_{a o} 、 V_{b o} 、 V_{c o}$. Fig. 15 is line-to-line voltage $V_{a b} 、 V_{b c} 、 V_{c a}$. Fig. 16 is phase voltage $V_{a n} 、 V_{b n} 、 V_{c n}$. Fig. 17 is load current $I_{a}$ 、 $I_{b} 、 I_{c}$.

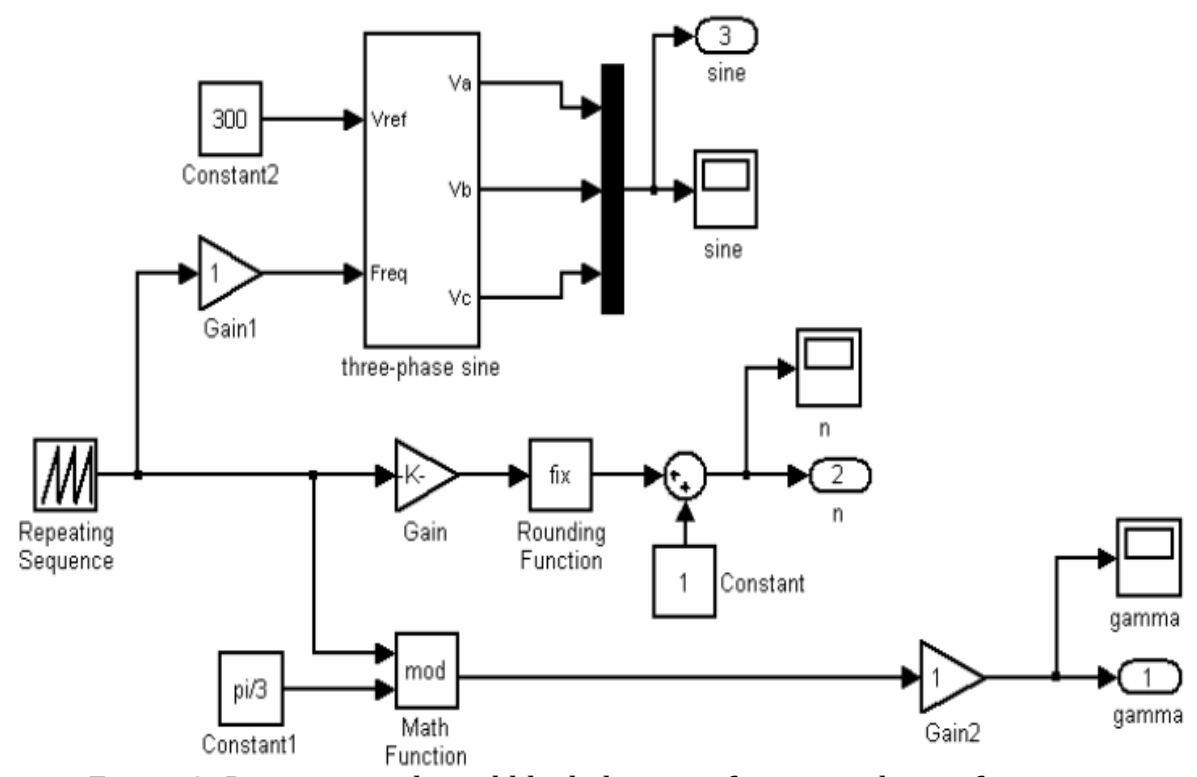

Figure 9: Rotation angle and block diagram for interval transformation

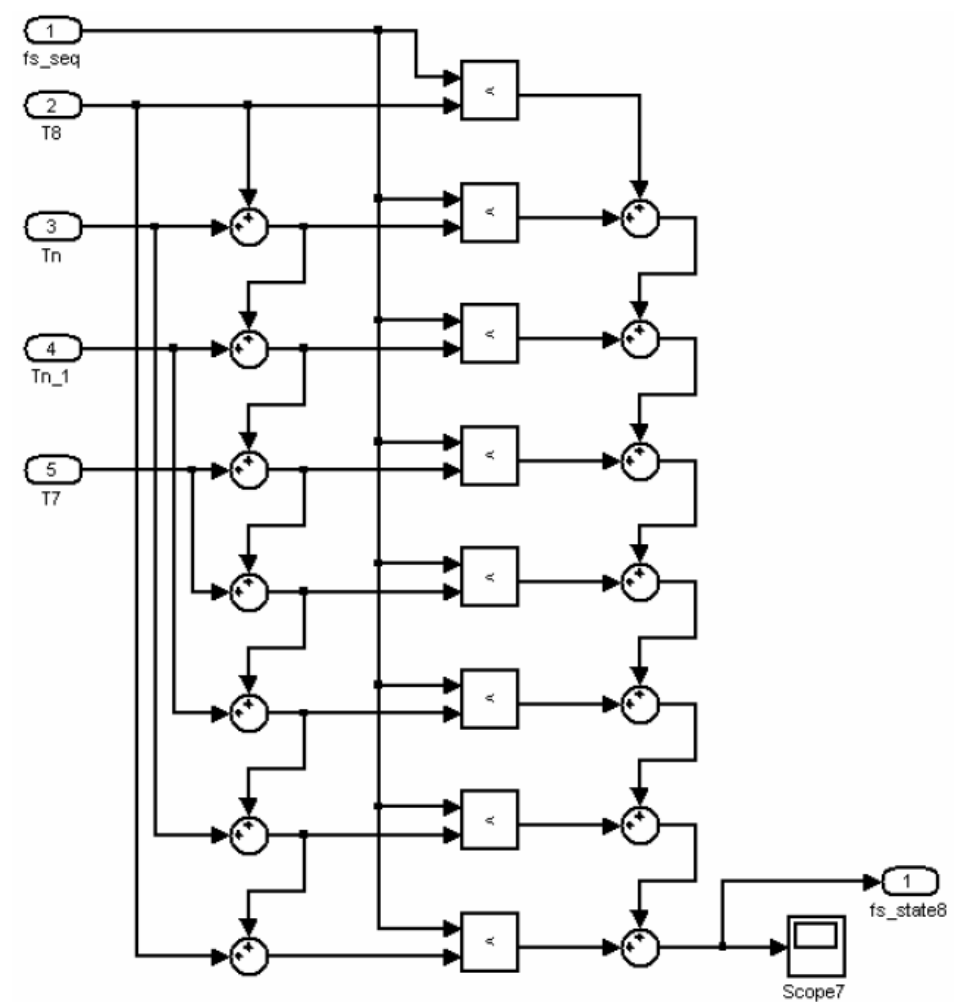

Figure 10: $f_{\text {S_state8 }}$ block diagram 

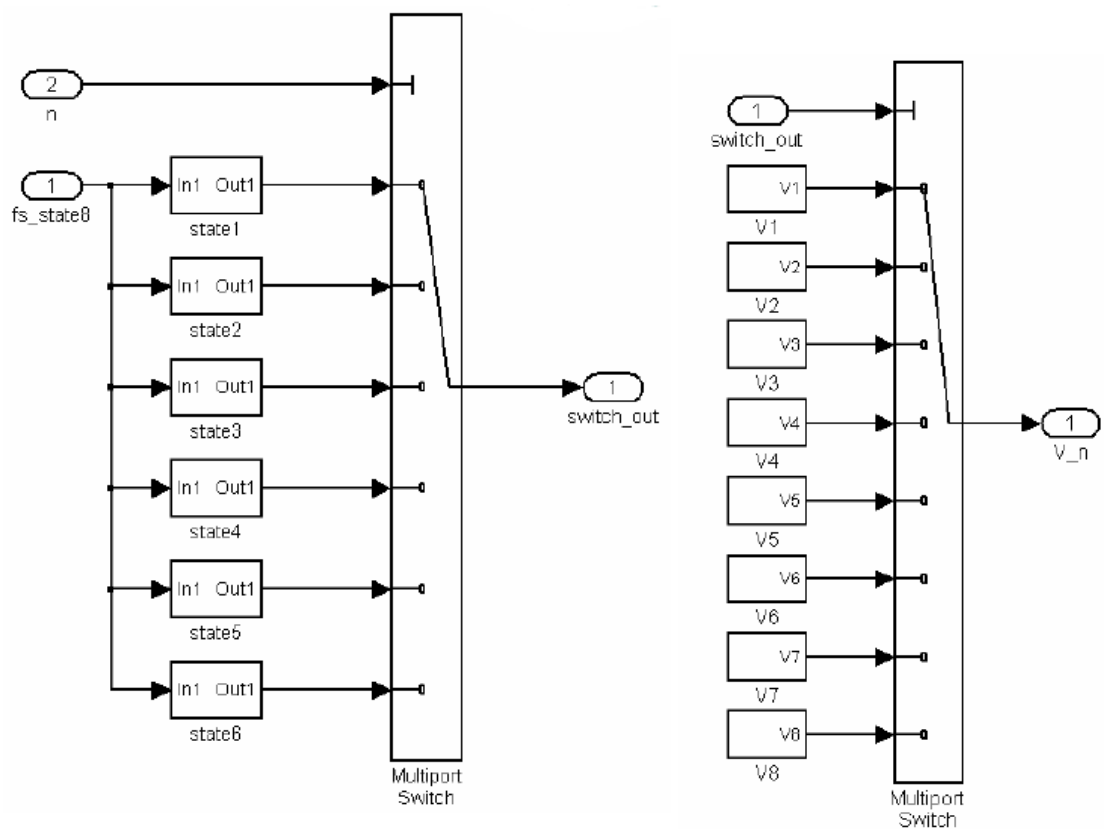

Figure 11: Sn_out block diagram

Figure 12: $V_{-}$n block diagram
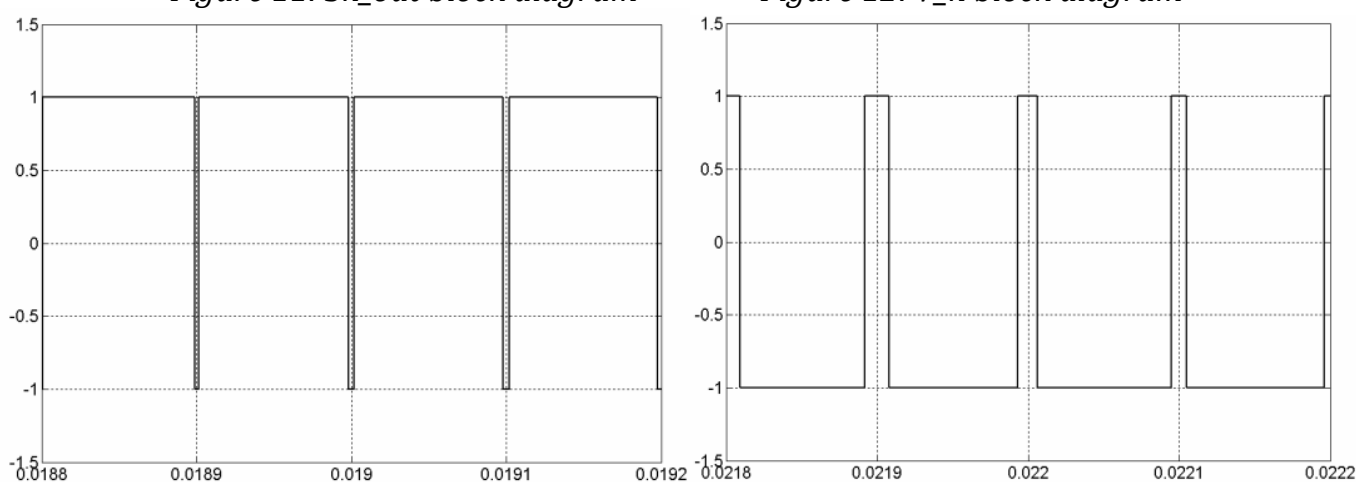

(a) Section I

(b) Section II

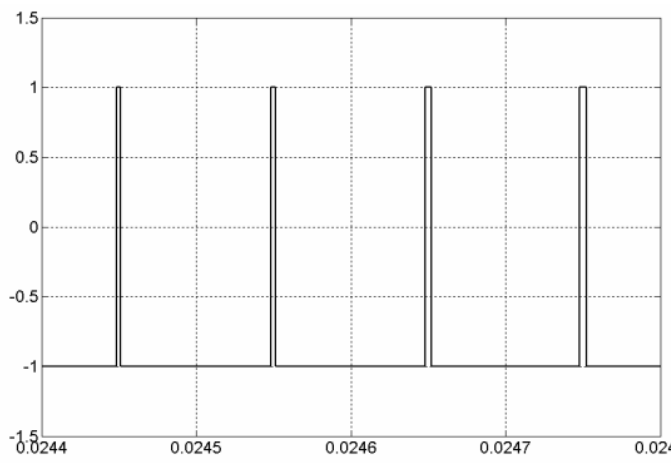

(c) Section III

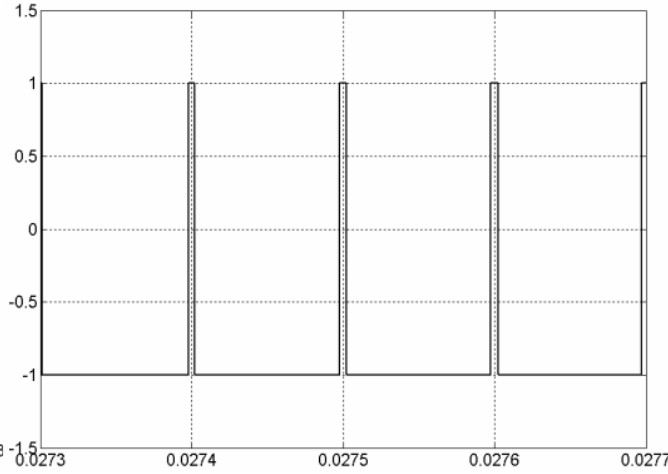

(d) Section IV
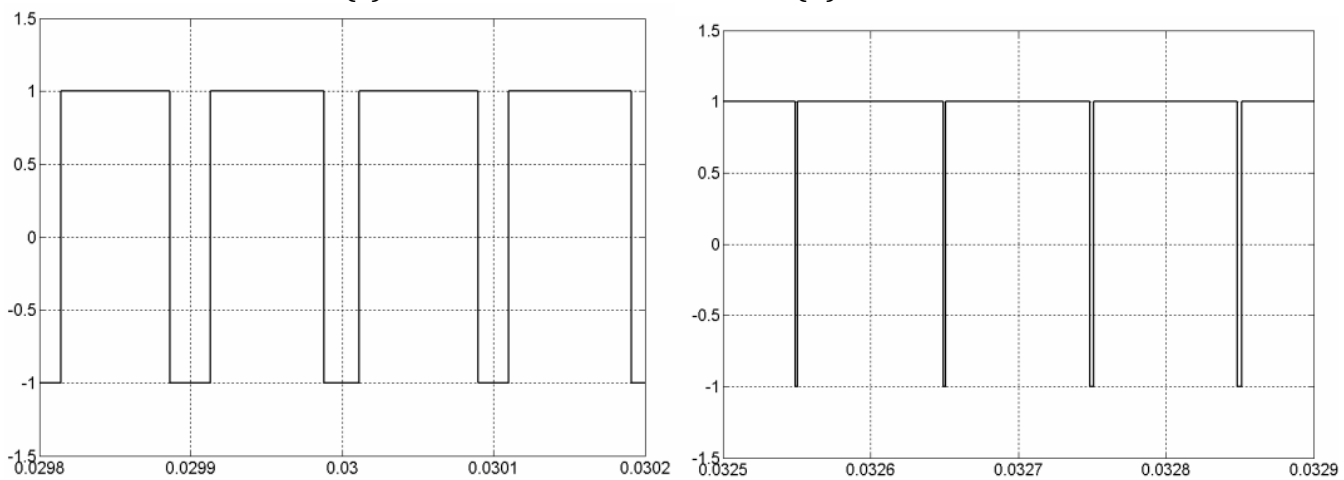

Figure 13: Voltage space vector wave width modulation waveform 


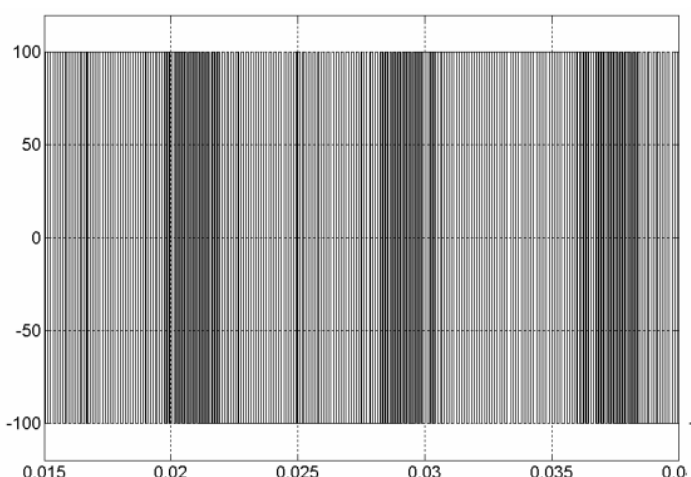

(a) Vao

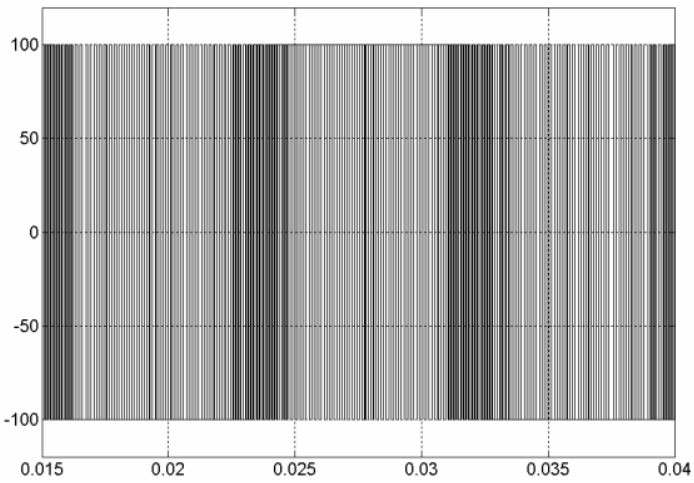

(c) $\mathrm{Vco}$

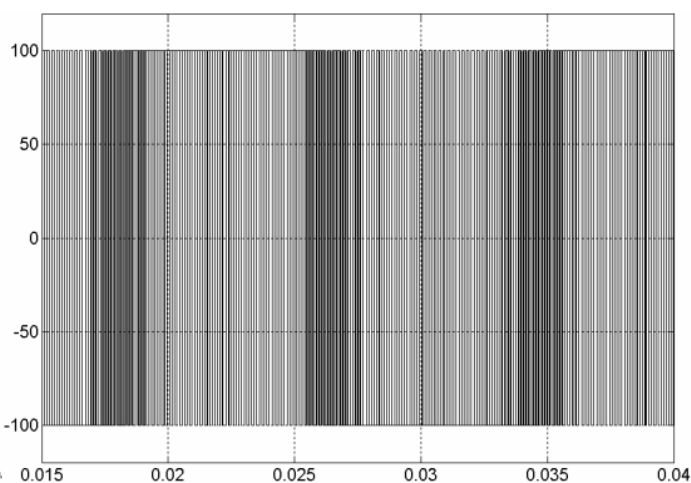

(b) $\mathrm{Vbo}$

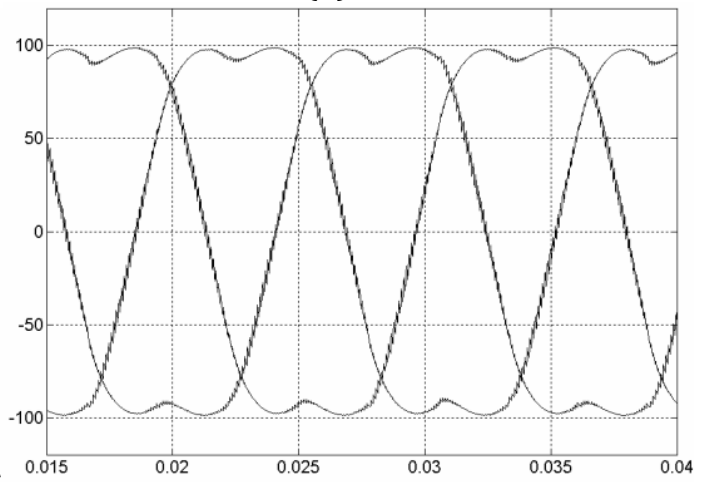

(d) Vao, Vbo, Vco of After filtering

Figure 14: wave form of output voltage Vao、Vbo、Vco

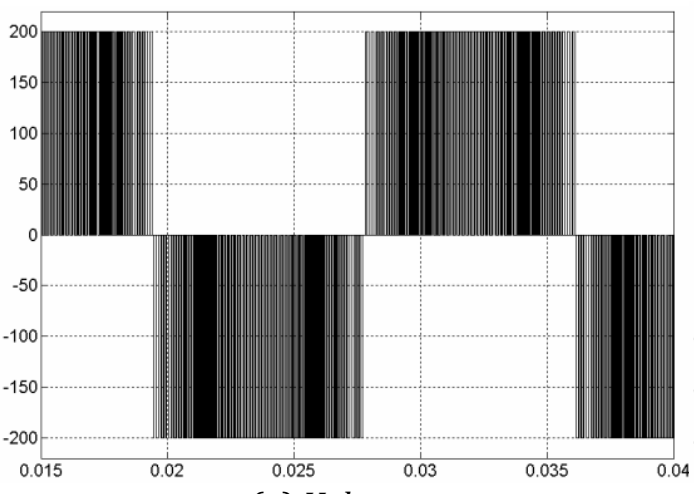

(a) $\mathrm{Vab}$

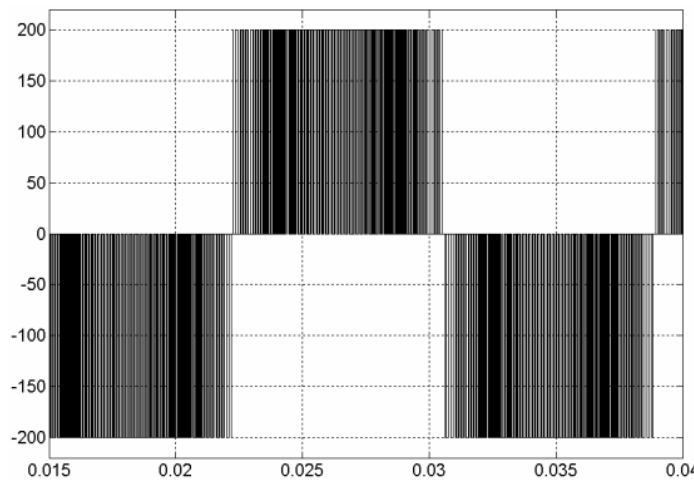

(c) $\mathrm{Vca}$

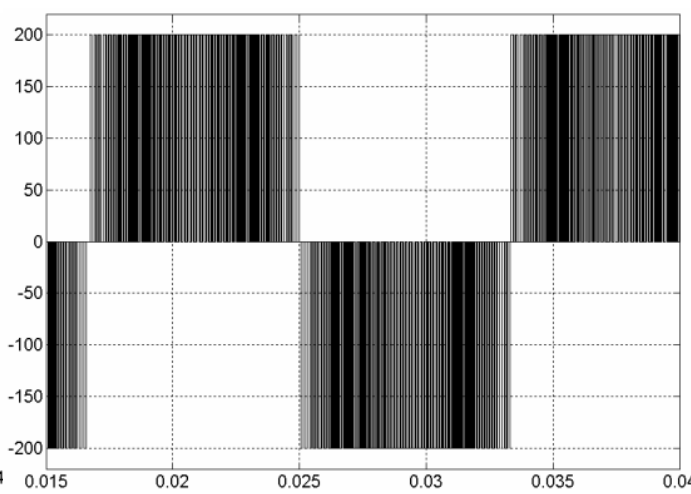

(b) $V b c$

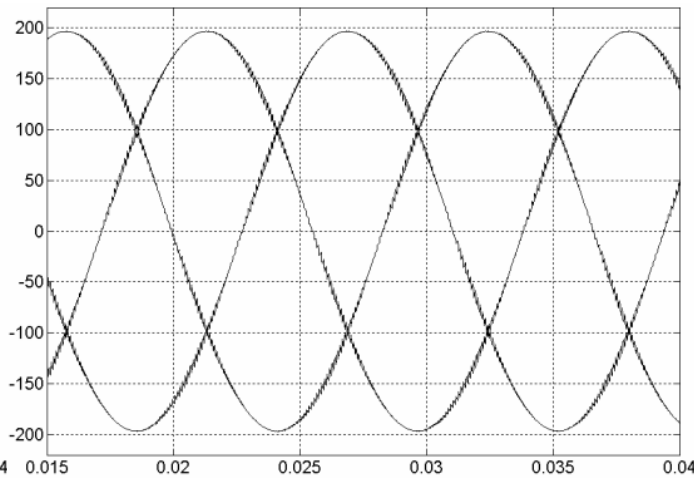

(d) $V a b 、 V b c 、 V c a$ of After filtering

Figure 15: Line to line voltage $V a b 、 V b c 、 V c a$ 


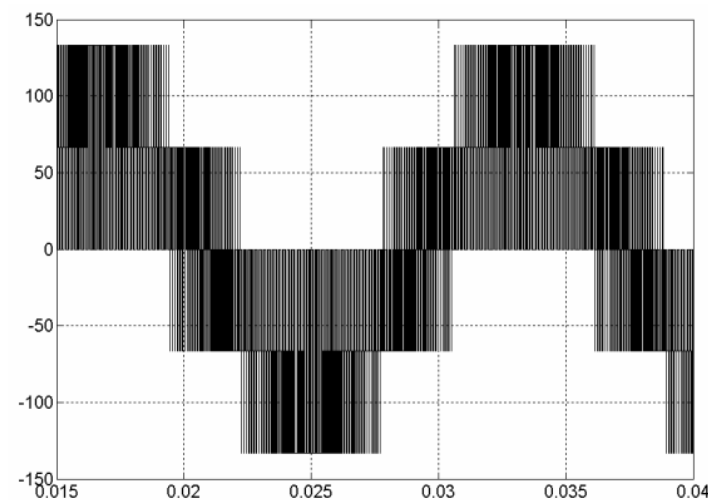

(a) Van

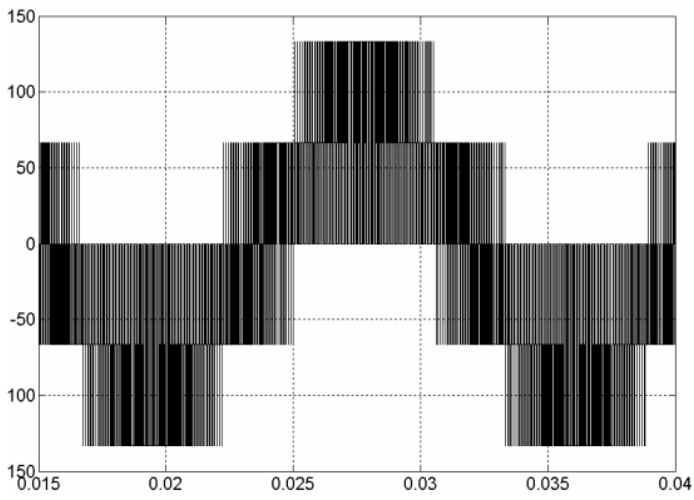

(c) $V c n$

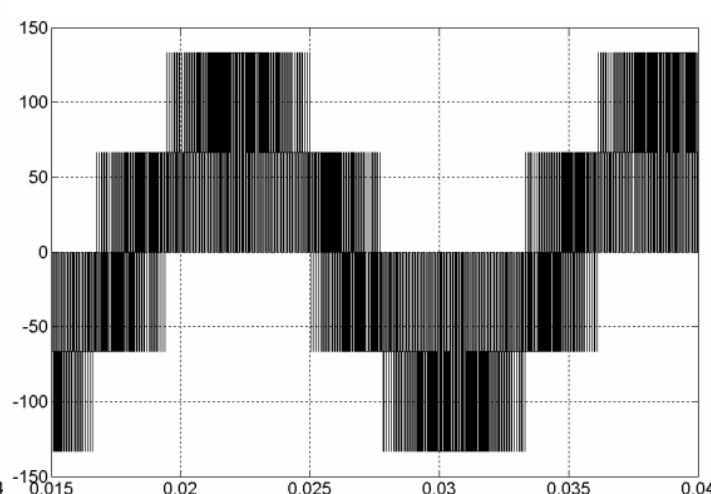

(b) $\mathrm{Vbn}$

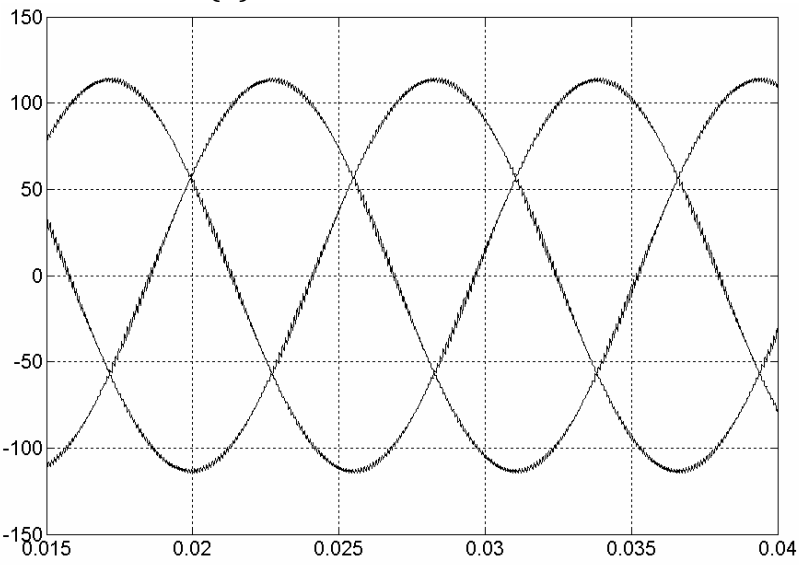

(d) Van $V b n 、 V c n$ of After filtering

Figure 16: Phase voltage Van,Vbn、Vcn

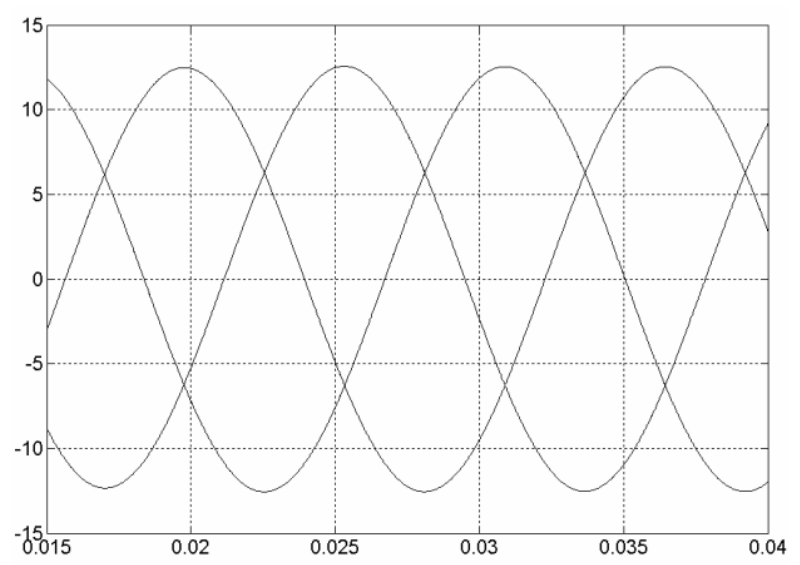

Figure 17: Load current Ia 、Ib、Ic

\subsection{Results of test}

According to the simulation results, cascaded multilevel converters are developed by using microcontrollers and programmable logic modules to verify the control of SVPWM technology on cascaded multilevel converters. The actual load test of the output of multilevel converters is carried out by a 1 horsepower motor.

The following will be divided into $60 \mathrm{~Hz}, 50 \mathrm{~Hz}$ and $30 \mathrm{~Hz}$, in the case of output frequency of the various modulation index $(1,0.7,0.2)$, the input voltage is $120 \mathrm{~V}$. Fig.18 is the output of various modulation indices under the output frequency $60 \mathrm{~Hz}$.

Fig. 19 is the output of various modulation indices under the output frequency $50 \mathrm{~Hz}$.

Fig.20 is the output of various modulation indices under the output frequency $30 \mathrm{~Hz}$.

From the output of the modulation index, it can be seen that the instantaneous fluctuation of the voltage signal is small, and the total harmonic distortion rate is low, which is basically consistent with the simulation results. 


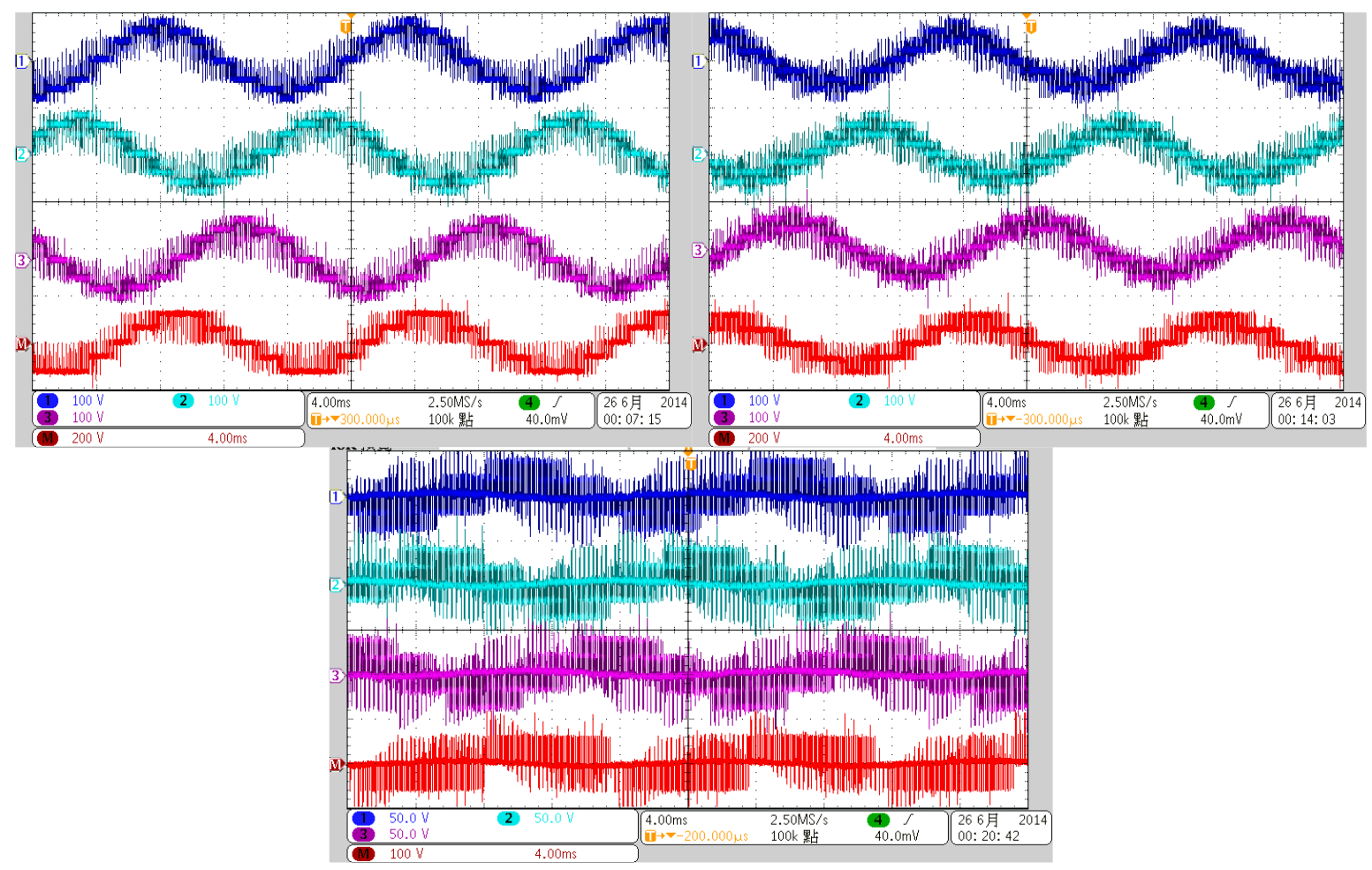

Figure 18: output frequency $60 \mathrm{~Hz}$, modulation index 1, CH1 CH3 Van, Vbn、Vcn, load is $1 \mathrm{HP}$ motor.

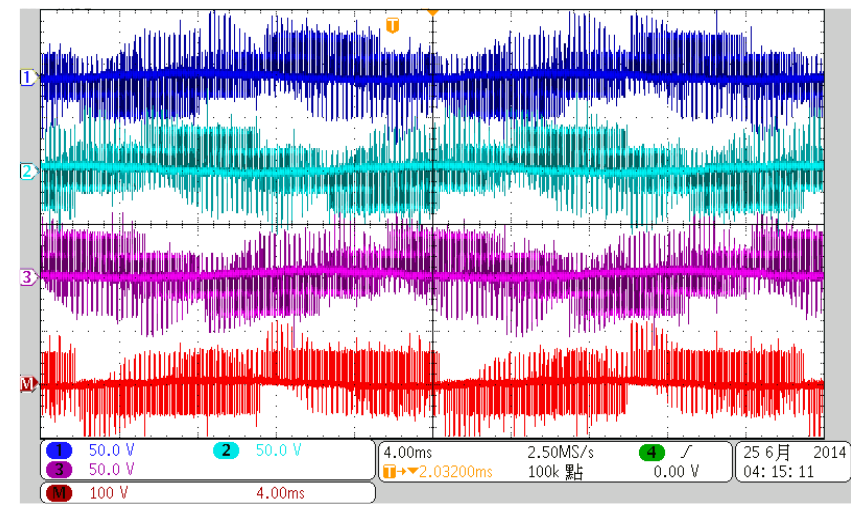

Figure 19: output frequency $50 \mathrm{~Hz}$, modulation index 1, CH1 CH3 Van 、Vbn、Vcn, load is $1 \mathrm{HP}$ motor.

This paper uses MATLAB Simulink software to simulate and analyze the system, and makes the hardware circuit to complete the cascade multilevel converter. Then, the feasibility of the control system circuit is verified by the results of simulation and actual measurement.

The simulation and experimental results show that SVPWM technology can be well applied to cascaded multilevel converters, and the output voltage fluctuation rate is small, and the overall utilization rate is high.

\section{References}

[1] Yao Zhiqing, Yu Fei, Zhao Qian, Zhang Qun, "Simulation Study of Large-scale PV Gridconnected System Based on Modular Multilevel
Converter [J]", Chinese Journal of Electrical Engineering, 2013, Volume 49, Issue 6, Pages 1720.

[2] Yang Xiaofeng, Lin Zhiqin, Zheng Qionglin, You Xiaojie, "A review of modular multilevel converters[J]", Chinese Journal of Electrical Engineering, 2013, Volume 61, Issue 6, Pages 8185.

[3] Guan Minyuan, Xu Zheng, Tu Qingrui, Pan Weiyong, "Modular multilevel converter HVDC transmission regulation strategy[J]", Power system automation, 2015, Volume 72, Issue 2, Pages 51-55.

[4] Zhao Yao, Zhao Gengshen, Guo Tianyong, Zhao Xingyu, Yin Jie, "Research and Application of Low Harmonic Dead-time Algorithm Based on SVPWM 
[J]", Power System Protection and Control, 2012, Volume 61, Issue 8, Pages 12-21.

[5] Hou Shiying, Song Xing, Sun Tao, Zhang Chuang, "A novel fault-tolerant three-phase four-switch grid-connected inverter based on space vector hysteresis control[J]", Power System Protection and Control, 2013, Volume 32, Issue 2, Pages 6168.

[6] Zhao Ke, Sun Dongyang, Wang Guanglin, "Fourswitch three-phase square-wave brushless $D C$ motor flux tracking control[J]", Journal of Motor and Control, 2012, Volume 38, Issue 4, Pages 17 23.

[7] Yang Kun, Zhao Jin, Wang Rui, "Fault tolerance and control strategy of three-phase PWM rectifier under arm damage[J]", Electrical Drive, 2015, Volume 46, Issue 8, Pages 12-27.

[8] Zhao Ke, An Quntao, Sun Li, "PMSM sensorless control system with staggered inverter[J]", Journal of Motor and Control, 2010, Volume 42, Issue 4,
Pages 18-25.

[9] Wen Xiaoling, Yin Xiang-gen, Zhang Zhe, "Implementation of unified space vector PWM for three-phase inverter[J]", Journal of Electrical Technology, 2013, Volume 81, Issue 10, Pages 12-19.

[10] He Zhengyi, Ji Xuewu, Qu Wenlong, "A novel SVPWM compensation algorithm based on Deadtime online adjustment [J]", Journal of Electrical Technology, 2015, Volume 39, Issue 6, Pages 19-23.

[11] Huang Jin, Xiong Rui, Wang Zhi, "SPWM control strategy for suppressing common mode interference of inverter with three-phase four-leg [J]", Journal of Electrical Technology, 2014, Volume 36, Issue 3, Pages 76-81.

[12] He Zongyuan, Sun Dan, He Yikang, "PMSM DTC system three-phase four-switch fault-tolerant operation", Power Electronics Technology, 2013, Volume 39, Issue 2, Pages 82-87. 